\title{
Therapeutic approaches enhancing peripheral nerve regeneration
}

\author{
M. Egle De Stefano ${ }^{1,2,3^{*}}$, Francesca Toni ${ }^{4 *}$, Valerio D’Orazi ${ }^{4,5}$, Andrea Ortensi ${ }^{4,5}$, Ada Maria Tata ${ }^{1,3 \#}$ \\ ${ }^{1}$ Dip. di Biologia e Biotecnologie Charles Darwin, Sapienza Università di Roma, Roma, Italy \\ ${ }^{2}$ Istituto Pasteur-Fondazione Cenci Bolognetti, Sapienza Università di Roma, Roma, Italy \\ ${ }^{3}$ Centro di Ricerca in Neurobiologia "Daniel Bovet", Sapienza Università di Roma, Roma, Italy \\ ${ }^{4}$ Unità di Microchirurgia Generale e Chirurgia della Mano, Casa di Cura Accreditata Fabia Mater, Roma, Italy \\ ${ }^{5}$ Dipartimento di Scienze Chirurgiche, Sapienza, Università di Roma, Roma, Italy. \\ Email: \#adamaria.tata@uniroma1.it
}

Received 21 March 2013; revised 12 May 2013; accepted 24 May 2013

Copyright (C) 2013 M. Egle De Stefano et al. This is an open access article distributed under the Creative Commons Attribution License, which permits unrestricted use, distribution, and reproduction in any medium, provided the original work is properly cited.

\begin{abstract}
Peripheral nerve injury is a common occurrence and represents a major economic burden for society. The development of novel strategies to enhance peripheral nerve regeneration is, therefore, of great relevance. Conventional treatments include surgical repair of the damaged nerves for minor injuries, whereas autologous nerve grafts are required to recover longer interruptions. However, despite great surgical advances, functional recovery is often poor. Although it is well known that the peripheral nervous system has a greater regenerative capacity than the central nervous system and, considering the scientific advancements and knowledge in regenerative medicine, clinical applications appears still limited. This review provides an overview of the methodological approaches currently under study, aimed at enhancing peripheral nerve regeneration. In particular, tissue engineering, cell therapy and pharmacological approaches will be discussed.
\end{abstract}

Keywords: Nerve Fibers; Regeneration; Schwann Cells; Scaffolds; Cell Therapy

\section{INTRODUCTION}

Large part of peripheral neuropathies is due to traumatic events that include motor accidents, falls, sportrelated injuries, among others. Transected nerves rapidly undergo Wallerian degeneration, therefore a delayed intervention may limit functional recovery. So far, the surgical treatment appears the first possible therapy;

*First two authors equally contributed to this work

${ }^{\#}$ Corresponding author. however, type of injury and correct nerve reapposition can dramatically influence the success of surgical interventions. Direct nerve repair (end-to-end) is preferred when the gap along a nerve is short and the two edges of the damaged nerve can be sutured with minimal tension [1]. However, when nerve gap is too long and does not allow an end-to-end repair methodology, the autologous nerve grafting may be necessary. On the other hand, autologous nerve graft is limited by the availability of donor nerves and donor site morbidity [2]. In even more severe cases, when the proximal stump of the injured nerve is unavailable, surgical alternatives may be used, such as end-to-side neurorrhaphy [3]. In any case, finding the right conditions to accelerate nerve rigeneration allows to reach the best results, with complete recovery of sensory-motor functionality. An alternative approach for nerve repair is to develop synthetic nerve conduits to suture the gaps between the proximal and distal nerve stumps and promote nerve regeneration. A conduit for in vivo application should form a suitable environment for nerve regeneration by combining cellular stimulating factors and biodegradability. Moreover, it should be non-toxic and easily made-up in convenient sizes and shapes. In addition, its permeability, swelling and mechanical strength should be tunable, as it is known to play a relevant role for axon elongation in vivo. Finally, an ideal scaffold for nerve regeneration should combine mechanical properties to prompt Schwann cell (SC) adhesion and proliferation, as well as axon elongation.

\section{STRUCTURAL COMPONENTS FOR NERVE REPAIR}

Nerve conduits (NCs) represent a promising alternative 
to conventional treatments for peripheral nerve repair. Materials for NC production should be biodegradeable, possess adequate mechanical properties, and allow exchange of nutrients. NCs must fulfill several requirements, as they should 1) be biocompatible, 2) have sufficient mechanical stability during nerve regeneration, 3) be flexible, 4) be porous, to ensure supply of nutrients, and 5) degrade into non-toxic products after bridging the gap, to prevent long-term inflammation. Biodegradable NCs have been made out of various materials of either biological or synthetic origin. Natural-derived materials have good cell compatibility, but they often need extensive purification. Furthermore, the majority of them lacks adequate mechanical strength and water stability [4].

\subsection{Natural Compounds}

Natural polymers are advantageous materials for tissue engineering of nerves as they are biocompatible and favor migration of supporting cells avoiding toxic effects. However, their poor mechanical properties and the relatively fast biodegradation in vivo generally limits their applications as materials constituent of external tubular structures. Natural compounds preferentially used are: collagen, gelatin, silk fibroin, alginate, chitosan, agarose and hyaluronic acid [5].

We performed experiments using two types of experimental paradigms of sciatic nerve regeneration. In one modality, sciatic nerves were exposed at their exit from under the gluteus muscle (Figure 1(A)) and excised. In a first approach, we practiced the end to end regenerative condition, in which in the two stumps of the sharply cut nerve were sutured, perfectly aligned, with a nylon thread (9/0) (a procedure called neurorraphy) (Figures 1(B) and (C)). In same animals, the sutured site was surrounded by a sleeve made of a biological substrate, the ester of hyaluronic acid (HYAFF-11, or hyalophill; Fidia Farmaceutics, Abano Terme, PD, Italy) (Figure 1(D)), which was instead omitted in animals used as controls. In the second paradigm, we resected about $1 \mathrm{~cm}$ of the nerve (Figures 1(G) and $(\mathbf{H})$ ) and connected the two stumps with tube made of purified porcine collagen I and III (Figures 1(I) and (L)). Rats were killed three months after surgery and the part of the nerve distal to the injury site was cut into transverse semithin and ultrathin sections for light and electron microscopy investigation, respectively. At this time, nerves appeared reconstituted (Figures 1(E) and (F)), neurorraphy + hyalophill paradigm), as the two stumps were perfectly re-connected.

By morphological analysis on semithin sections, we observed a partial regeneration of myelinated and unmyelinated axons, in both neurorraphy without (Figures 2(A)-(C)) and with (Figures 2(D) and (E)) hyalophill application. However, a higher degree of axon myelination
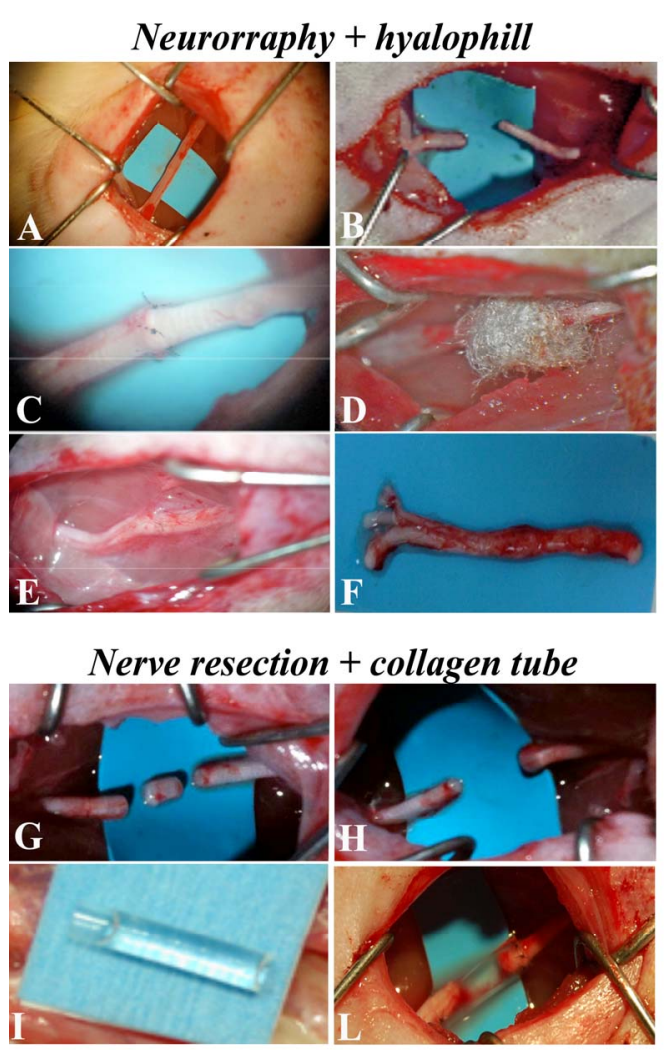

Figure 1. (A-F) End-to-end neurorraphy. Sciatic nerve, exposed at its exit from the gluteus muscle (A), is sharply cut in two stumps (B), later sutured in perfect alignment $(\mathrm{C})$ and surrounded by a sleeve of hyalophill at the site of suture (D). Three months later, the nerve appears integer, surrounded by its perineurium. (G-L) Nerve resection. Nerves are resected, by cutting off about $1 \mathrm{~cm}(\mathrm{G}, \mathrm{H})$, the two end stumps are inserted into a collagen tube (I, L), made of purified porcine collagen type I + III, and sutured.

and restoration of pre-surgery conditions was evident in those nerves treated with the biological compound. In both conditions, re-myelinated axons were more evident at the outer border of the nerves (Figures 2(A) and (B), -hyalophill; Figures 2(D) and (E), +hyalophill), respect to the center (Figure 2(C), -hyalophill), possibly beneficing of factors released by the perineurium itself.

This characteristic was more evident in the hyalophilltreated specimens, as the amount of more centrally located unmyelinated axonal figures was predominant. Quantitative analysis, obtained by counting the number of myelinated axons over the total, showed a significant increase in axon regeneration and myelination in nerves treated with hyalophill, compared with the control (Figure 2(F)). Differently from these two conditions, sciatic nerves re-grown into the collagen tube appeared regenerated, with largely re-myelinated axons (Figures 2(G) and (H)). These observations were in accord with the fol- 

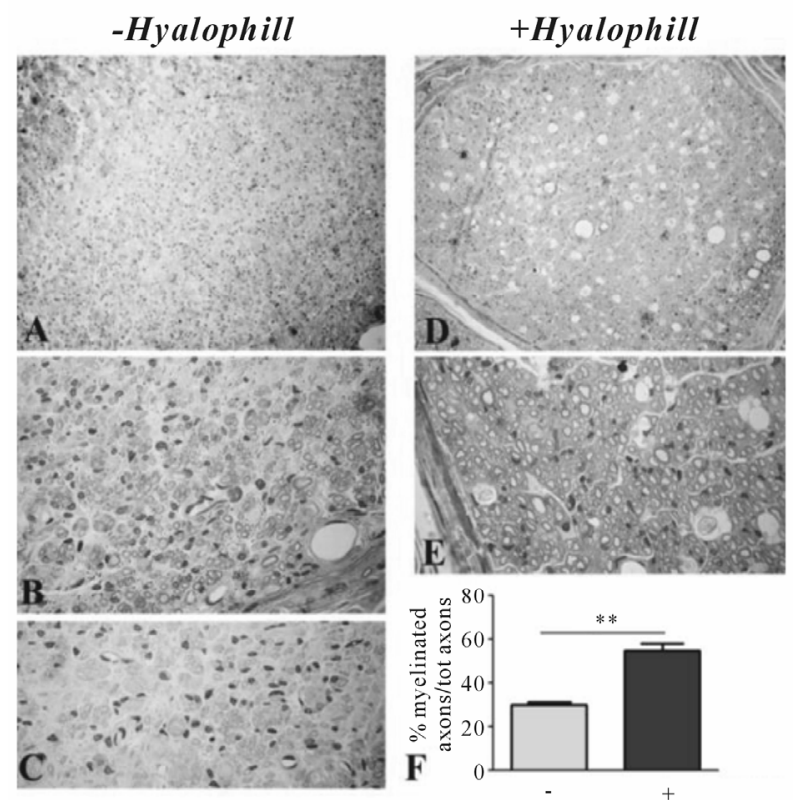

Hyalofil

+Collagen tube
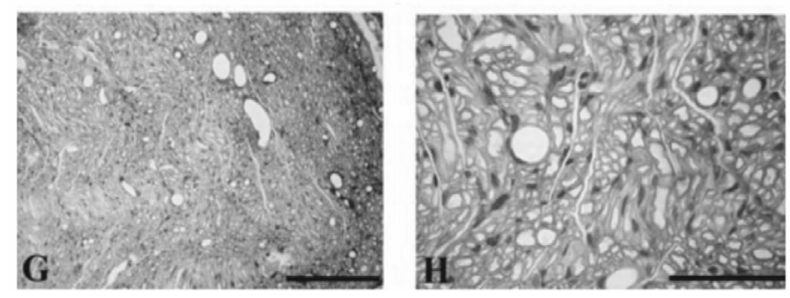

Figure 2. Transverse semithin sections obtained from control (-hyalophill) and treated (+hyalophill) nerves after neurorraphy (A-E), and from resected nerves with successive application of a collagen conduit $(\mathrm{G}, \mathrm{H})$, three months after surgery. (A-E) Regenerated axons, myelinated and non-myelinated, are preferentially distributed in the outer areas of the nerve, closer to the perinerium, a condition more evident in control animals (A, B). Here, myelinated axons appear quite small in diameter (B), while the larger ones, not properly myelinated, are located more central in the nerve $(\mathrm{C})$. In sciatic nerves treated with hyalophill, presence of myelinated axons is more evident $(D, E)$, although figures of axon degeneration are easily recognizable (E). Count of myelinated axons over the number of total axons shows a significantly ( $p<0.01$ by Student's t-test) higher number in nerves treated with hyalophill respect to controls $(\mathrm{F})$. $(\mathrm{G}, \mathrm{H})$ Three months after nerve resection and application of a collagen tube connecting the two nerve stumps, almost all axons appear regenerated in all nerve parts. Scale bars: A, D and $\mathrm{G}, 500 \mu \mathrm{m} ; \mathrm{B}, \mathrm{C}, \mathrm{E}$ and $\mathrm{H}, 200 \mu \mathrm{m}$.

lowing ultrastructural analyses. Nerves sutured without addition of hyalophill showed several regenerated axons, mostly grouped inside one fascicle, usually surrounded by abundant collagen (Figure 3(A)), and intervalled by regenerated small unmyelinated fibers. Recovered myelin sheaths, however, appeared a bit loose at points, suggesting a non-perfect assembly, or an ongoing reorganization. Numerous axons were, instead, characterized by different degrees of suffering (Figure 3(B)), with some of them collapsed and encircled by disrupted or extremely disarranged myelin sheaths. These figures could represent different stages of abortive regeneration, as also suggested by numerous fascicles formed by completely degenerated axons embedded in remnants of myelin-based material (Figure 3(C)). Alternatively, they may be expression of an altered cross talk between neurons and SCs, which are not able to form a proper myelinating coat. In the experiments of neurorraphy with

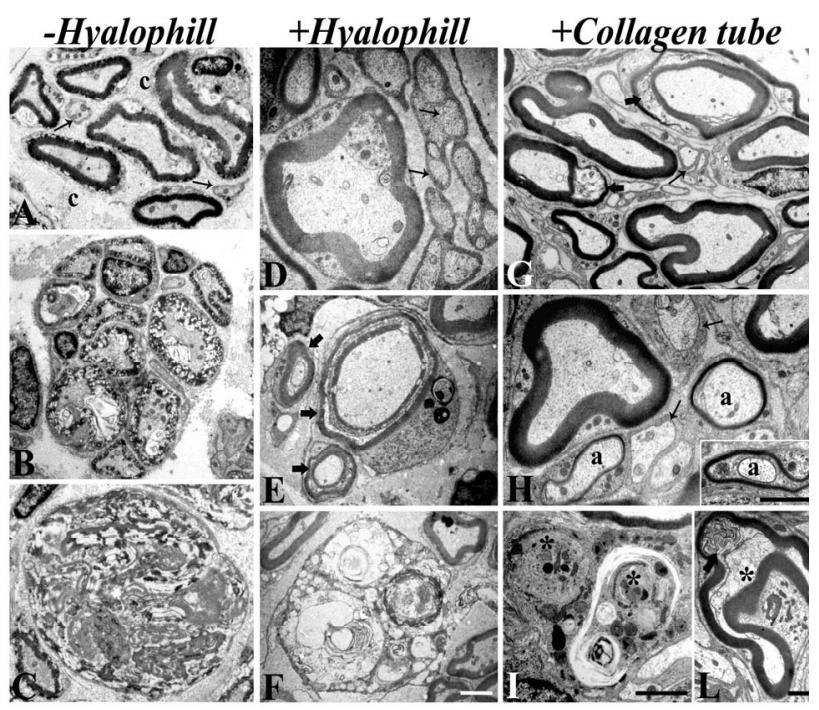

Figure 3. Electron micrographs of transversal sections of sciatic nerves subjected to neurorraphy, without (A-C) or with (D-F) hyalophill treatment, and of resected sciatic nerves with successive application of a porcine collagen (I + III) tube (G-L), three months after surgery. (A-F) Regenerated axons, with compact myelin sheath and healthy axoplasm, are present in both conditions ( - and + hyalophill). However, in the -hyalophill specimens, myelin sheaths tend to be less compact than in the hyalophill-treaded nerves (A, -hyalophill; D, +hyalophill). Unmyelinated axons, intermixed with the myelinated ones, are also regenerated (arrows in A and D). In -hyalophill nerves, though, a high number of axons with different degrees of degenerations, often occurring in fascicles, are observed (B). Large figures of remnants of myelin sheaths are also present $(\mathrm{C})$. In the hyalophill-treated nerves, numerous axons display an immature myelin coat in evident formation (block arrows in E), although a number of degenerating, or degenerated, axons are also present (F). (G-L) In resected nerves allowed to grow into a collagen tube, almost all axons, both myelinated and non-myelinated (arrows in $\mathrm{G}, \mathrm{H}$ ), are regenerated. Myelin sheaths are thick and compact, with only a few exceptions showing points of rearrangements (block arrows in $\mathrm{G}, \mathrm{L}$ ). A number of medium caliber axons (a in $\mathrm{H}$ and inset) have very thin myelin sheaths, in evident stage of formation. A few figures of phagocytosed axons into Schwann cells (asterisks in I) and of degenerating axons, often surrounded by a largely compact myelin sheath (asterisk in L) are observed. Differently long scale bars all correspond to $2 \mu \mathrm{m}$, with the following correspondence: A-C, G and L; D, H and inset to fig H; E, F; I. 
addition of hyalophill, regenerated myelinated axons were characterized by a thick and compact myelin sheath (Figure 3(D)) and others were in the process to complete their myelination (Figure 3(E)). However, clusters of degenerating axons, usually intermixed with healthy ones, were also observed (Figure 3(E)). In the second experimental paradigm, which makes use of the collagen tube, myelinated axons were almost all perfectly regenerated, with thick and compact myelin sheaths. Some of them, usually the smaller diameter axon still displayed a thin rim of myelin, in the process of completing its formation (Figure 3(H) and inset). Phagocyte figures of axonal debris within SCs were occasionally observed (Figure 3(I)), as well as degenerating axons (Figure 3(L)). Differently from the other two treatments, however, degenerating axons were encircled by an apparently healthy myelin sheath, suggesting the intervention of connectivity problems only after axon regeneration had successfully occurred. All these results corroborate and reinforce what has been described in the literature, indicating a beneficial role of biological substrates applied to the site of damage and collagen scaffold on axonal regeneration. Moreover, our data strongly suggest that collagen conduits, although applied to severely damaged nerves (resection of a consistent portion of the nerve), are more efficient for axonal regeneration than external application of biological compounds.

In some cases, a combination between natural and synthetic polymers has been proposed, to join the biocompatibility of natural components with the mechanical performance of the synthetic material [6]. More natural polymers have been used as inner fillers for NCs, in the form of fibers, channels, porous sponges, or hydrogel matrices as delivery vehicles for cells, growth factors, or pharmacological drugs. Moreover, the inner layer can covalently bound RDG peptides (Arg-Gly-Asp), sequences typically present in extracellular matrix components (ECM) such as laminin and fibronectin. Adhesion of RDG peptides to natural or synthetic scaffolds may represent an alternative approach to the use of native ECM proteins able to promote cell adhesion and axon elongation [7].

\subsection{Synthetic Polymers}

Recent research has focused on the production of artificial nerve guides, which can degrade within the host with just a mild reaction. Biodegradable materials offer several advantages, such as the possibility of incorporating $\mathrm{SCs}$, or bioactive molecules, through physicochemical modifications of the polymers, and deliver them during biodegradation. Another interesting property is that their flexibility, biocompatibility, mode of degradation, porosity and mechanical strength may be changed by modifying their chemical properties [5].
Scaffolds of polyglycolic acid (PGA), poly-DLlactide-caprolactone (PLCL) and poly [(lactic acid)-co (glycolitic acid)-alt-(L-lysine)] (PLGL), are used as NCs, but present some limitations, such as induction of inflammation and local concentration of acid residues deriving from their biodegradability in the surrounding tissues [8]. In alternative, hydrogels can be considered an interesting option to rigid hydrophobic materials.

For example, poly(amidoamines) (PAAs), synthetic water-soluble polymers, are biocompatible and the products derived from their biodegradability are not toxic [9]. Several PAA hydrogels have been tested with success as substrates for culturing cells as SCs or dorsal root ganglia (DRG) neurons [10,11].

\section{CELL AND TISSUE THERAPY}

Although novel approaches have largely improved the knowledge on the type of nerve conduits more appropriate for nerve regeneration, their use is limited in the case of too long $(>0.7 \mathrm{~cm})$ nerve gaps. Under these circumstances, nerve auto-grafts, or the muscle-in-vein approach (described ahead) appear, so far, the best solutions for repairing this type of nerve injury [12]. Recently, great attention has been focused on the use of natural or synthetic conduits, enriched in different cell types, which may contribute to nerve regeneration.

\subsection{Muscle-in-Vein}

To improve nerve repair, the possibility of a conduit obtained combining a vein tract with fresh skeletal muscle fibers, has been largely experimented by several authors $[13,14]$. The rationale of the muscle-in-vein approach is that muscle prevents vein collapse, while the vein wall prevents axon dispersion and represent a natural tube, within which axon elongation can occur [13]. On the other hand, the use of fresh muscle fibers appear relevant, if considering that muscle basal lamina enhances the migratory properties of resident SCs. In fact, it has been demonstrated, by confocal microscopy, that SCs and regenerating axons successfully colonize the muscle-invein grafts already two weeks after surgery $[15,16]$. Moreover, in muscle fiber denervation, as well as in SCs deprived of their axons, over-expression of neuregulin (NRG)/erbB receptors has been observed [17]. Overexpression of this gliogenic factor and of its receptors appears relevant for supporting Schwann cell proliferation, indicating that the muscle-in-vein approach enhances nerve regeneration because it supports Schwann cell proliferation and migration.

\subsection{Schwann Cells}

It is well known that the peripheral nervous system (PNS) has a greater regenerative capacity than the central one 
(CNS). It is thought that this different regenerative capacity is due to a greater permissive environment in the PNS respect to the CNS, which is likely to be provided by SCs. These have a repertoire of physiological roles, including protection and regulation of nutritive exchanges with axons, myelin production and digestion of axon and myelin debris under pathological conditions. SCs help peripheral nerve regeneration, considering their ability to proliferate, migrate and release growth factors during development or after nerve lesion. Nerve injury alters the SC-axon interaction, which results in SCs de-differentiation and activation of their growth-promoting phenotype. At the proximal stump of a cut nerve, SCs re-enter in proliferative state and produce several substances, such as laminin, integrins and growth factors $[18,19]$. Morover, SCs form the bands of Büngner, important structures for directing regenerating axons across the lesion site [20,21].

Tissue engineering techniques may offer a potential solution to clinical problems by favoring seeding of SCs in artificial nerve conduits [22]. In fact, several experimental evidences showed that SCs may be cultured and expanded on nerve conduits, such as the PLGL-RGD peptide conjugated or polyamidoamine hydrogels [8, 11,23]. However, cultured SCs have limited clinical applications. The requirement of nerve donor material evokes additional morbidity and the time required to culture and expand the cells would delay the treatment. Instead, the ideal transplantable cells should be easily accessible, proliferate rapidly in culture and successfully integrate into the host tissue with immunological tolerance [24].

\subsection{Mesenchimal Stem Cells}

Mesenchimal stem cells (MSCs) are an attractive cell source for nerve tissue regeneration, as they are able to self-renew with a high growth rate and possess multi potent differentiation properties. There are also some evidences indicating that the MSCs may be non-immunogenic, or at least hypo immunogenic [25]. MSC fibroblast-like cells can be isolated from the stromal cell population found in a number of tissues. In particular, bone marrow and adipose tissue have been identified as main sources of these cells [26,27]. Currently, adipose tissue appears the most promising source of MSCs, considering that it can be easily and non-invasively lipoaspirated from the patient. Recent studies have shown that, following differentiation with a cocktail of growth factors (bFGF, PDGF, GGF-2), MSCs express Schwann cell markers such as GFAP, low affinity neurotrophic factor receptor $\mathrm{p} 75$, and calcium binding protein $\mathrm{S} 100$ beta [22]. It is of considerable clinical relevance to address the differentiation of human-derived MSC into
SC-like cells. This alternative source of cells, which is relatively simple to isolate and expand in culture, may be easily obtained from the same patients affected by nerve injury and, once addressed to the SC phenotype, represents an excellent tool to support and guide nerve regeneration in combination with appropriate scaffolds.

\subsection{Olfactory Ensheating Cells}

Olfactory unsheathing cells (OECs) are glial cells associated to the olfactory system displaying SC or astrocyte-like cell properties [28]. They support axons originating from olfactory epithelium and projecting into the olfactory bulb. Considering the great difficulty of CNS to regenerate axons, it appears relevant that, after olfactory nerve transection, cell regeneration in the olfactory epithelium is facilitated by the close association with OECs $[29,30]$. OECs normally do not form myelin, but they can do so after transplantation into demyelinated lesions. OECs are also able to produce neurotrophic factors, such as nerve growth factor (NGF) and brain derived-neurotrophic (BDNF), and have great migratory ability [31]. For these and other reasons, transplantation of OECs has been considered as an alternative source of cell-supporting peripheral nerve repair. Several researchers have already collected OECs from the olfactory bulb, supporting the idea that these cells may provide a potential autologous source of cells to reduce the risk of immunological rejection in case of auto-transplantation [32]. Corroborating this hypothesis, is the demonstration that OEC engraftment into axotomized facial nerve enhances axonal sprouting [33,34].

\section{ADDITIVE COMPOUNDS}

Medical treatments have achieved limited success in restoring functions to severely injured nerves. The combination of synthetic conduits and chemical molecules able to promote neurite outgrowth (e.g. NGF) has been recently considered as an additional strategy to better enhance nerve regeneration [23].

\subsection{Neurotrophic Factors}

Neurotrophic factors are a family of growth factors playing important roles in the natural process of nerve growth and regeneration [35]. Principal factor of this family is the nerve growth factor (NGF), first isolated by Levi Montanlcini in 1950 [36]. NGF prevents, or reduces, neuronal degeneration in animal models of neurodegenerative diseases [37] and appears to be involved in several psychiatric disorders [38]. As suggested by in vitro and in vivo studies, NGF enhances peripheral nerve regeneration and promotes myelin repair [39]. Considering its multiple functions, it has been proposed its potential 
use in peripheral nerve repair therapies. As above reported, the introduction of SCs into natural or synthetic scaffolds, in order to support and guide nerve regeneration, has been proposed based on the fact that SCs are main NGF producers [40]. However, studies orientated toward the identification of new and sophisticated NGF delivery system to mimic the natural process of secretion are emerging. First evidences indicate that a controlled release of NGF by microspheres, or by adenoviruses expressing this factor, increases the functional recovery of injured peripheral nerves, although the organic solvent used for the NGF-microspheres production might compromise NGF activity [41], NGF directly added within nerve conduits may be an alternative for local treatments. NGF immobilized on gelatin membranes, or PLGL scaffolds, promotes Schwann cell adhesion and survival in vitro and neurite outgrowth from pheochromocytoma (PC12) cells, indicating this approach potentially useful for the generation of nerve conduits for clinical nerve repair [23].

\subsection{Glial Growth Factor}

Glial Growth Factor (GGF) is factor produced by neurons, known to stimulate glial cells growth and differentiation and SC proliferation. Considering the role of SC in peripheral nerve development and regeneration, it appeared relevant to evaluate the ability of this factor in peripheral nerve regeneration [42]. GGF, introduced into conduits used to repair $2-4 \mathrm{~cm}$ peroneal nerve gaps in rabbit, caused an increase in SC number, accompanied by significant axonal regeneration [43].

\subsection{Acetylcholine Mimetics}

Acetylcholine (ACh), is the main neurotransmitter in the CNS and PNS. However, when released from growing axons, ACh is capable of regulating growth, differentiation and plasticity during nervous system development [44]. Moreover, it can act either both as stimulatory or inhibitory signal, as chemoattractant in spinal and sensory neurons $[45,46]$ and a direct regulation of $\mathrm{ACh}$ on neurite elongation in chick sensory neurons has been reported $[47,48]$. ACh can also control SC development; in fact, when it binds to muscarinic receptors type- 2 (M2), ACh can arrest SC proliferation and promote their differentiation [49,50]. Considering the dual role of ACh as modulating factor for neurite outgrowth and SC development, it may be relevant to investigate the potential effect of ACh in peripheral nerve regeneration. $\mathrm{ACh}$ is usually rapidly hydrolyzed by acetylcholinesterase and butirrylcholinesterase, largely produced in several tissues other than the nervous system. For this reason, addition of ACh to synthetic conduits may be not a successful strategy. In alternative, ACh mimetics are not hydrolyzed and for this reason they are more stable and may be used as additive compounds in combination with specific scaffolds. The potential application of ACh-like biomaterials in neural tissue engineering has been poorly investigated. More recently, it has been reported that ACh-like biomimetic polymers can promote neuritic sprouting and extension in explanted DRGs, and growth of hippocampal neurons [51,52]. Thus, ACh mimetics associated to appropriate scaffolds may be potential new biomaterials to further investigate nerve repair in PNS as well as CNS.

\section{CONCLUSION}

Improvement of nerve regeneration and the outcome of clinical microsurgery in the treatment of nerve injuries have a great relevance in term of social impact. Several aspects require specific attention in the clinical treatment of the patients, among which the timing of nerve reconstruction. In fact, delay of nerve injury treatment may cause neurobiological alterations in neurons and Schwann cells, impairing nerve functional recovery and affect neuron survival. Although conventional nerve reconstruction techniques used in clinical practice can largely contribute to treat nerve lesions, the outcome is generally insufficient. Tissue engineering and nanotechnology are suggesting new research therapeutic approaches, potentially orientated to accelerate nerve regeneration and recovery of nerve functionality. As discussed in this review, most significant advances in nerve repair and regeneration have been achieved. Therefore, each of the therapeutic approaches discussed appears limited. More recent studies report that combined treatments are more promising therapies. In fact, the use of an appropriate scaffold integrated with cells (i.e. autologous mesenchimal stem cells differentiated in SCs) and growth factors may represent the successful strategy to achieve better results in the clinical treatment of the peripheral nerve lesions.

\section{ACKNOWLEDGEMENTS}

The personal data was supported by Monte dei Paschi di Siena (A.O.); by Sapienza, Universiy of Roma funds (A.M.T.) and ASI (Agenzia Spaziale Italiana) grants (M.E.D.S.). F. Toni's fellowship was supported by MPS funds.

\section{REFERENCES}

[1] Beris, A., Lykissas, M., Korompilias, A. and Mitsionis, G. (2007) End-to-side nerve repair in peripheral nerve injury. Journal of Neurotrauma, 24, 909-916. doi:10.1089/neu.2006.0165

[2] Lundborg, G. (2002) Enhancing posttraumatic nerve regeneration. Journal of Peripheral Nervous System, 7, 
139-140. doi:10.1046/j.1529-8027.2002.02019.x

[3] Beris, A. and Lykissas M.G. (2009) Experimental results in end-to-side neurorrhapy. International Review Neurobiology, 87, 269-279. doi:10.1016/S0074-7742(09)87013-X

[4] Harley, B.A., Leung, J.H., Silva, E.C.C.M. and Gibson, L. J. (2007) Mechanical characterization of collagenglycosaminoglycan scaffolds. Acta Biomaterials, 3, 463- 474. doi:10.1016/j.actbio.2006.12.009

[5] Chiono, V., Tonda-Turo, C. and Ciardelli, G. (2009) Artificial scaffolds for peripheral nerve reconstruction. International Review Neurobiology, 87, 173-198. doi:10.1016/S0074-7742(09)87009-8

[6] Chiono, V., Ciardelli, G., Vozzi, G., Vozzi, F., Salvadori, C., Dini, F., Carlucci, F., et al. (2009) Melt extruded guides for peripheral nerve regeneration. Biomed Microdevices, 11, 1037-1350. doi:10.1007/s10544-009-9321-9

[7] Yan, Q.J., Li, J., Li, S.P. and Zhang, P. (2008) Synthesis and RDG peptide modifications of poly(lactic acid)-co[(glycolic acid)-alt-(L-lysine)]. ePolimers, 28, 1-12.

[8] Magnaghi, V., Conte, V., Procacci, P., Pivato, G., Cortese, P., Cavalli, E., Pajardi, G., Ranucci, E., Fenili, F., Manfredi, A. and Ferruti, P. (2011) Biological performance of a novel biodegradable polyaminodoamine hydrogel as guide for peripheral nerve regeneration. Journal Biomedical Materials Research, 98, 19-30. doi:10.1002/jbm.a.33091

[9] Franchini, J., Ranucci, E., Ferruti, P., Rossi, R. and Cavalli, R. (2006) Synthesis, physicochemical properties, and preliminary biological characterizations of a novel amphoteric agmatine-based poly(amidoamine) with RGDlike repeating units. Biomacromolecules, 7, 1215. doi:10.1021/bm060054m

[10] Jacchetti, E., Emilitri, E, Rodighiero, S., Indrieri, M., Gianfelice, A., Lenardi, C., Podestà, A., Ranucci, E., Ferruti, P. and Milani, P. (2008) Biomimetic poly(amidoamine) hydrogels as synthetic materials for cell culture. Journal Nanobiotechnology, 6, 1-14. doi:10.1186/1477-3155-6-14

[11] Mauro, N., Manfredi, A., Ranucci, E., Procacci, P., Larus, M., Antonioli, D., Mantovani, C., Magnaghi, V. and Ferruti, P. (2013) Degradable poly(aminodoamine) hydrogels as scaffolds for in vitro culturing of peripheral nervous system cells. Macromolecular Bioscience, 13, 332-347. doi:10.1002/mabi.201200354

[12] Battiston, B., Raimondo, S., Tos, P., Goidano, V., Audisio, C., Scevola, A., Perroteau, I. and Geuna, S. (2009) Tissue engineering of peripheral nerves. International Review Neurobiology, 87, 227-249. doi:10.1016/S0074-7742(09)87011-6

[13] Brunelli, G.A., Battiston, B., Vigasio, A., Brunelli, G. and Marocolo, D. (1993) Bridging nerve defects with combined skeletal muscle and vein conduits. Microsurgery, 14, 247-251. doi:10.1002/micr.1920140407

[14] Battiston, B., Tos, P., Cushway, T. and Geuna, S. (2000) Nerve repair by means of vein filled with muscle grafts. I. Clinical results. Microsurgery, 20, 32-36. doi:10.1002/(SICI)1098-2752(2000)20:1<32::AID-MICR

\section{6>3.0.CO;2-D}

[15] Geuna, S., Raimondo, S., Nicolino, S., Boux, E., Fornaro, M., Tos, P., Battiston, B. and Perroteau, I. (2003) Schwann-cell proliferation in muscle-vein combined conduits for bridging rat sciatic nerve defects. Journal Reconstruction Microsurgery, 19, 119-123. doi:10.1055/s-2003-37818

[16] Raimondo, S., Nicolino, S., Tos, P., Battiston, B., Giacobini-Robecchi, M.G., Perroteau, I., Geuna, S. (2005) Schwann cell behavior after nerve repair by means of tissue-engineered muscle-vein combined guides. Journal Comparative Neurology, 489, 249-255. doi:10.1002/cne.20625

[17] Nicolino, S., Raimondo, S., Tos, P., Battiston, B., Fornaro, M., Geuna, S. and Perroteau, I. (2003) Expression of alpha2a-2b neuregulin-1 is associated with early peripheral nerve repair along muscle-enriched tubes. Neuroreport, 14, 1541-1545. doi:10.1097/00001756-200308060-00029

[18] Fu, S.Y. and Gordon, T. (1997) The cellular and molecular basis of peripheral nerve regeneration. Molecular Neurobiology, 14, 67-116. doi:10.1007/BF02740621

[19] Magnaghi, V., Procacci, P. and Tata, A.M. (2009) Novel pharmacological approaches to Schwann cells as neuroprotective agents for peripheral nerve regeneration. International Review Neurobiology, 87, 295-315. doi:10.1016/S0074-7742(09)87015-3

[20] Frostick, S.P., Yin, Q. and Kemp, G.J. (1998) Schwann cells, neurotrophic factors and peripheral nerve regeneration. Microsurgery, 18, 397-405.

doi:10.1002/(SICI)1098-2752(1998)18:7<397::AID-MIC R2>3.0.CO;2-F

[21] Hall, S. (2005) The response to injury in the peripheral nervous system. Journal of Bone \& Joint Surgery, 87, 1309-1319.

[22] Li, Q., Ping, P., Jiang, H. and Liu, K. (2006) Nerve conduit filled with GDNF gene modified Schwann cells enhances regeneration of the peripheral nerve. Microsurgery, 26, 116-121. doi:10.1002/micr.20192

[23] Yan, Q., Yin, Y. and Binbin, L. (2012) Use new PLGLRGD-NGF nerve conduits for promoting peripheral nerve regeneration. Biomedical Engineering Online, 11, 36. doi:10.1186/1475-925X-11-36

[24] Tohill, M. and Terenghi, G. (2004) Stem cell plasticity and therapy for injuries of the peripheral nervous system. Biotechnologies Applied Biochemistry and Biotechnology, 40, 17-24. doi:10.1042/BA20030173

[25] Barry, E.P. and Murphy, J.M. (2004) Mesenchymal stem cells: clinical applications and biological characterization. International Journal Biochemical Cell Biology, 36, 568-584. doi:10.1016/j.biocel.2003.11.001

[26] Strem, B.M., Icok, K.C., Zhu, M., Wulur, I., Alfonso, Z., Schreiber, R.E., Fraser, K.J. and Hedrick, M.H. (2005) Multipotential differentiation of adipose tissue derived stem cells. Keio Journal Medicine, 54, 132-141. doi:10.2302/kjm.54.132

[27] Caddick, J., Kingham, P.J., Gardiner, N.J. Wiberg, M., Terenghi, G. (2006) Phenotypic and functional cha- 
racteristic of mesenchymal stem cells differentiated along a Schwann cell lineage. Glia, 54, 840-849.

doi:10.1002/glia.20421

[28] Devon, R. and Doucette, R. (1992) Olfactory ensheathing cells myelinate dorsal root ganglion neurites. Brain Research, 589, 175-179.

doi:10.1016/0006-8993(92)91182-E

[29] Carr, V.M. and Farbman, A.I. (1992) Ablation of the olfactory bulb up-regulates the rate of neurogenesis and induces precocious cell death in olfactory epithelium. Experimental Neurology, 115, 55-59. doi:10.1016/0014-4886(92)90221-B

[30] Li, Y., Field, P.M. and Raisman, G. (1997) Repair of adult rat corticospinal tract by transplants of olfactory ensheathing cells. Science, 277, 2000-2002. doi:10.1126/science.277.5334.2000

[31] Radtke, C., Kocsis, J.D. and Vogt, P.M. (2009) Transplantation of oltactory ensheating cells for peripheral nerve regeneration. International Review Neurobiology, 87, 405-415. doi:10.1016/S0074-7742(09)87022-0

[32] Marshall, C.T., Lu, C., Winstead, W., Zhang, X., Xiao, M., Harding, G., Klueber, K.M. and Roisen, F.J. (2006) The therapeutic potential of human olfactory-derived stem cells. Histology Histopathoogy, 21, 633-643.

[33] Guntinas-Lichius, O., Angelov, D.N., Tomov, T.L., Dramiga, J., Neiss, W.F. and Wewetzer, K. (2001) Transplantation of olfactory ensheathing cells stimulates the collateral sprouting from axotomized adult rat facial motoneurons. Experimental Neurology, 172, 70-80. doi:10.1006/exnr.2001.7774

[34] Deumens, R., Koopmans, G.C., Lemmens, M., Mollers, S., Honig, W.M., Steinbusch, H.W., Brook, G. and Joosten, E.A. (2006) Neurite outgrowth promoting effects of enriched and mixed OEC/ONF cultures. Neuroscience Letters, 397, 20-24.

doi:10.1016/j.neulet.2005.11.063

[35] Richardson, P.M. (1991) Neurotrophic factors in regeneration. Current Opinion Neurobiology, 1, 401-406. doi:10.1016/0959-4388(91)90061-B

[36] Levi Montalcini, R. (1987) The nerve growth factor 35 years later. Science, 237, 1154-1162. doi:10.1126/science.3306916

[37] Tuszynski, M.H. and Blesch, A. (2004) Nerve growth factor: From animal models of cholinergic neuronal degeneration to gene therapy in Alzheimer's disease. Progress Brain Research, 146, 441-449. doi:10.1016/S0079-6123(03)46028-7

[38] Hempstead, B.L. (2006) Dissecting the diverse actions of pro-and mature neurotrophins. Current Alzheimer Research, 3, 19-24. doi:10.2174/156720506775697061

[39] Sun, W., Sun, C., Lin, H., Zhao, H., Wang, J., Ma, H., Chen, B., Xiao, Z. and Dai, J. (2009) The effect of collagen-binding NGF-beta on the promotion of sciatic nerve regeneration in a rat sciatic nerve crush injury model. Biomaterials, 30, 4649-4656. doi:10.1016/j.biomaterials.2009.05.037

[40] Rutkowski, G.E., Miller, C.A., Jeftinija, S. and Malla- pragada, S.K. (2004) Synergistic effects of micropatterned biodegradable conduits and Schwann cells on sciatic nerve regeneration. Journal of Neural Engineering, 1, 151-157. doi:10.1088/1741-2560/1/3/004

[41] Xu, X., Yu, H., Gao, S., Mao, H.Q., Leong, K.W. and Wang, S. (2002) Polyphosphoester microspheres for sustained release of biologically active nerve growth factor. Biomaterials, 23, 3765-3772. doi:10.1016/S0142-9612(02)00116-3

[42] Terenghi, G. (1999) Peripheral nerve regeneration and neurotrophic factors. Journal of Anatomy, 194, 1-14. doi:10.1046/j.1469-7580.1999.19410001.x

[43] Mohanna, P.N., Terenghi, G. and Wiberg, M. (2005) Composite PHB-GGF conduit for long nerve gap repair: A long-term evaluation. Scandinavian Journal of Plastic and Reconstructive Surgery and Hand Surgery, 39, 129137. doi:10.1080/02844310510006295

[44] Nguyen, L., Rigo, J.M., Roche, V., Belachew, S., Malgrange, B., Rogister, B., et al. (2001) Neurotransmitters as early signals for central nervous system development. Cell and Tissue Research, 301, 187-202. doi: $10.1007 / \mathrm{s} 004410000343$

[45] Zheng, J.Q., Felder, M., Connor, J.A. and Poo, M. (1994) Turning of nerve growth cones induced by neurotransmitters. Nature, 368, 140-144. doi:10.1038/368140a0

[46] Kuffler, D.P. (1996) Chemioattraction of sensory growth cones by diffusible concentration gradients of acetylcholine. Molecular Chemical Neuropathology, 28, 199-208. doi:10.1007/BF02815223

[47] Tata, A.M., Cursi, S., Biagioni, S. and Augusti, T.G. (2003) Cholinergic modulation of neurite outgrowth and neurofilament expression in developing chick sensory neurons. Journal Neuroscience Research, 73, 227-234. doi:10.1002/jnr.10650

[48] Bernardini, N., Srubek, T.G., Tata, A.M., Augusti-Tocco, G. and Biagioni, S. (2004) Detection of basal and potassium-evoked acetylcholine release from embryonic DRG explants. Journal Neurochemistry, 88, 1533-1539. doi:10.1046/j.1471-4159.2003.02292.x

[49] Loreti, S., Vilaró, M.T., Visentin, S., Rees, H., Levey, A.I. and Tata, A.M. (2006) Rat Schwann cells express M1-M4 muscarinic receptor subtypes. Journal Neuroscience Research, 84, 97-105. doi:10.1002/jnr.20874

[50] Loreti, S., Ricordy, R., De Stefano, M.E., Augusti-Tocco, G. and Tata, A.M (2007) Acetylcholine inhibits cell cycle progression in cultured rat Schwann cells by activation of M2 receptor subtype. Neuron Glia Biology, 3, 269-279. doi:10.1017/S1740925X08000045

[51] Gumera, C.B. and Wang, Y. (2007) Modulating neuronal responses by controlled integration of acetylcholine-like functionalities in biomimetic polymers. Advances Materials, 19, 4404-4409. doi:10.1002/adma.200701747

[52] Tu, Q., Li, L., Zhang, Y., Wang, J., Liu, R., Li, M., Liu, W. and Wang, X. (2011) The effect of acetylcholine-like biomimetic polymers on neuronal growth. Biomaterials, 32, 3253-3264. doi:10.1016/j.biomaterials.2011.01.044 